\title{
A Hammer only sees Nails: Why Construction Contractors Monetise Social Value
}

\section{Greg Watts ${ }^{1}$ and Anthony Higham ${ }^{1}$}

${ }^{1}$ School of Science, Engineering and Environment, University of Salford, UK Keywords: Construction, Social Value, Corporate Social Responsibility, Legislation.

\section{Abstract:}

Corporate Social Responsibility (CSR) in the UK construction industry has been growing in awareness and expectation over the previous decades. Whilst at first the focus of CSR was on environmental issues; more recent developments have shifted the focus onto the Social Value (SV) aspects of CSR. Such a change has been driven by changing stakeholder demands and the introduction of the Public Services (Social Value) Act (2012). Contractors now need to measure their CSR and SV in order to effectively communicate with stakeholders. Such SV measurement needs to be understood by a plethora of stakeholders, be accurate, and withstand scrutiny. However, there exists at the heart of SV a conflict between its subjective nature and the objective way SV is often measured. This objectivity manifests itself in the use of quantitative variables such as the monetisation of SV. Monetary figures are easy to communicate and universally understood. However, reducing SV to monetary metrics arguably misses the wider positive impacts, and the accuracy and reliability of such measurement tools can also be questioned. It therefore needs to be asked that if monetary metrics are increasingly used for SV measurement, does this result in the wider SV benefits being missed. There is also a gap in literature around how exactly contractors measure SV and why, and what the ramifications of this are. This paper aims to explore this gap and help understand construction contractor SV measurement behaviour, motivations and knock on

effects. Semi-Structured interviews are conducted with staff from ten construction contractors. The results reveal monetary methods of SV measurement are widely adopted despite acknowledgements over their limitations, as they are easier to conduct and easier to communicate. This paper contributes to the construction management literature with an understanding of contractor SV measurement motivations and practices. 


\section{INTRODUCTION}

Construction is a significant industry for the UK economy and represents approximately $9 \%$ of economic output (BEIS, 2018). The public sector represents around $26 \%$ of this workload and offers a degree of certainty in uncertain economic times. For any construction contractor wanting to secure public sector projects the Social Value Act (2012) is now used throughout public procurement. The Act can be described as the step forward on the organisational CSR journey that reappeared in the 1950's. This places obligations on private sector companies to adopt socially responsible practices and participate in activities that increase social value. Through placing a legal obligation on the public sector, the Social Value Act formalised and legitimised the use of social value as a procurement criterion to match that of cost, time and quality; contracts would no longer be let on a lowest upfront cost basis. This places a requirement on construction contractors to measure and communicate their social value in order to be successful in public sector procurement.

As social value is arguably a subjective concept, measurement and communication could prove difficult. To circumvent any potential problems that may arise because of this subjectivity, contractors adopt objective measurement methods. Why contractors engage with SV measurement has been explored, but how this engagement occurs, and the ramifications of any measurement practices adopted is yet to be fully understood. Through interviews with ten leading UK construction contractors this paper seeks to address this gap in current knowledge.

\section{FROM CSR TO SV}

Amongst the plethora definitions published, the 'CSR pyramid' first proposed by Carroll in 1979 , then further developed in 1991, has served as somewhat of a seminal base for CSR research with its wide-ranging encompassing approach to the subject. Carroll (1991) argues that a company's CSR journey starts with their economic responsibilities, then moves to their legal responsibilities, then ethical responsibilities before finally arriving (at the top of the pyramid) at philanthropic responsibility. This approach to defining CSR served as an allencompassing umbrella concept under which numerous interpretations and approaches exist (Barthorpe, 2010). 
The book Social Responsibilities of the Businessman by Bowen (1953) is credited with bringing to the forefront of modern business actions the age-old concept of general goodwill by those with the ability to make a positive difference. In the book it is wealthy business owners who are challenged to increase their social responsibility due to increasing post war prosperity (Bowen, 1953). The concept then grew throughout the 60's and 70's with the advent of social movements and the increased realisation that business behaviour could be shaped by stakeholder mobilisation (Carroll, 1999). This journey then took CSR and wider business responsibility through an evolution of sorts from social responsibility to more environmentally focussed strategies. Perhaps fuel for those who link business intentions with only superficial action to illustrate their responsibility for work winning purposes, a decline of CSR activity was witnessed in the 1980's which has been linked to the economic issues of the time. However, in defence of business, it can be argued that without economic certainty a company may not be able to operate in the long term let alone commit resources to socially responsible actions where they are not directly linked to business operations. This perhaps adds further credibility to the CSR pyramid definition proposed by Carroll (1991) as CSR is a philanthropic business priority only after economic, legal and ethical targets have been achieved. The prosperous 1990's brought a return of CSR to the forefront of business activity, but with a continued evolution of understanding and expectation. As business wealth and stakeholder involvement and demands increased over the millennium and into the last decade the focus of organisational CSR expanded (or perhaps arguably went full circle) to include all manner of social, economic, and environmental factors that business may be directly or indirectly involved in, or may be completely separate but judged of such societal importance there is an expectation upon all businesses to play their part. A recent industrially focussed global business survey confirms that CSR is now embraced by the majority of large-scale organisations as a central part of their business identity (KPMG, 2017). Whilst the motivations of the companies involved were not explored in great detail, it can be argued that their increasing adoption of socially responsible practices, in the UK at least, can be in part attributed to legislation increasing socially focussed criterion in public sector procurement practices.

One example of such legislation is The Public Services (Social Value) Act (2012) (SVA). The SVA governs public body procurement behaviour by legitimising the use of criterion in 
procurement other than purely financial (Watts et al., 2019a). The SVA allows public bodies to take additional social value achieved (as put forward by the tenderer) into consideration when awarding contracts so that the successful contractor is not necessarily the one who put forward the lowest immediate cost (Loosemore, 2016).

\section{THE CONSTRUCTION INDUSTRY}

The construction industry includes the design, construction, maintenance and demolition of built assets, engineering and infrastructure works. According to a UK Government briefing document in 2018 the construction industry contributed $£ 117$ billion to the UK economy, some $6 \%$ of the total, and is responsible for over 2.4 million jobs across 343,000 different businesses (Rhodes, 2019). Construction therefore has a significant impact upon the UK economic output. The public sector accounts for approximately $26 \%$ of UK construction work, and historic economic data has shown that public sector workload remains fairly buoyant during times of economic uncertainty (Rhodes, 2015).

This could help explain why contractors engage with the public sector despite the additional requirements imposed by the SVA. Managements philanthropic values and succumbing to the pressures imposed by wider stakeholder expectations cannot be underestimated as drivers of social value behaviour. Nevertheless, the SVA plays a key role in imposing social value requirements upon contractors who engage with public sector work. The introduction of the SVA therefore ultimately placed an obligation on any company wanting to win public sector work to be able to effectively measure and communicate their social value (Watson et al., 2016).

\section{MEASURING SOCIAL VALUE; THE BATTLE BETWEEN SUBJECTIVITY AND OBJECTIVITY}

In order to successfully communicate such SV an agreement must be reached on a definition, at a minimum between the company and client, but also ideally between a wide cohort of stakeholders (Watts et al, 2019). However, with no widely agreed definition between multiple stakeholders who each hold potentially unique interpretations, accurate measurement and clear communication is difficult to achieve (Loosemore and Higgon, 2016). Attempts to effectively communicate with wider cohorts simultaneously is arguably 
the problem at the heart of the CSR and SV debates, in that these concepts mean different things to different people (Watts et al, 2019a). Approaches can be categorised as objective or subjective. Objective is where a fact-based natural science approach is adopted that implies a phenomenon has an existence independent of social actors (Robson and McCartan, 2017). Subjective is where meanings are socially constructed and therefore subject to change (Bryman, 2016). Objective attempts to define CSR and SV are adopted by some parties but have ultimately led to competing and often conflicting definitions proposed that serve to further exacerbate attempts to reach a consensus amongst stakeholders (Zhao et al., 2012). Subjective attempts to define CSR allow each stakeholder when faced with the same communication to arrive at their own interpretation (Griffith, 2011). However, one problem that exists with such subjectivity is that it is open to potential abuse by some companies who mask their failure to effectively engage with CSR and SV with ambiguous and opaque terminology (Watts et al., 2019a). Whilst numerous different methods of measuring SV exist (Wood and Leighton, 2010; Higham et al, 2018), many that are currently adopted by construction contractors objectively quantify SV so that it can be easily communicated as part of tender returns. Indeed, it has been argued that social value has objective requirements in the need to be measured, communicated and widely understood (Loosemore and Higgon, 2016). A perspective that has been largely perpetuated on the view that social value is delivered through "investments that intentionally target specific social objectives along with a financial return and measure the achievement of both" (Social Impact Investment Taskforce, 2014:1).

Literature is dominated by an array of tools, metrics, frameworks and models that have been developed with the sole aim of predicting and measuring social value attainment. Proponents of these techniques such as Ding (2008) Carter and Fortune (2007), Rees (2009) and Higham et al (2018) argue such evaluation frameworks provide fundamental building blocks for comprehensive change, by providing practical, transparent and simple to understand criteria to which the industry can respond in manageable steps, thereby empowering construction professionals to think about sustainability in an experiential way, with the safety net of expert guidance, checks and balances (Schweber, 2013). Yet Haapio and Viitaniemi (2008), Ding (2008) and more recently Higham et al (2018) have questioned the validity of monetising sustainability, a theoretical construct far removed from the 
operation of the market mechanism. At the core of their objection is the assertion that monetary units are likely to limit the validity of any sustainability evaluation produced.

The most contentious issue in the adoption of such objective frameworks is the quantification and monetisation of intangible social outcomes using financial proxies (Arudson et al, 2013; Krley et al, 2013) which can lead analysts to take some extremely imaginative and adventurous pathways when appraising social return (Krley et al, 2013). Or lead contractors to apply retrospective social value justifications to achieve client requirements (Russel, 2013). Yet it is this objective need to quantify such a subjective concept that perpetuates the tension at the heart of SV debates. Contractors need to measure and communicate the subjectivity of SV and arguably choose an objective, monetary derived method by which to do this. Although this decision in itself is presumed yet not explored in any great detail in the literature. The ramifications of this process are also not fully understood. This paper seeks to explore how and why contractors engage with SV and understand any impact objectively measuring and communicating SV has on the concept's subjectivity.

\section{RESEARCH METHODOLOGY}

Ontology is questioning the nature of reality and consists of two dominant ontological positions; objectivism and constructivism (Bryman, 2016). As objectivism derives from the fact-based natural sciences, in the case of social value this approach is ultimately of a positivist epistemological position and therefore requires to be expressed through quantitative data i.e. many of the measurement tools currently used in the construction industry. Constructivism refers to a belief that meanings are socially constructed and agreed, and epistemologically is of an interpretivist position. This is where meanings are subjective and so best expressed through qualitative data. Social Value measurements ultimately find qualitative data difficult to quantify and so tend towards a quantitative approach.

The packaging of social value as quantitative data driven from an objectivist standpoint by many social value measurement tools adopted in the UK construction industry continues to dominate practice. This paper, however, subscribes to the argument that social value is best 
understood from a constructivist viewpoint. Indeed, it is through this approach that the views, perceptions, actions and motivations of construction contractors can be best understood (Cresswell, 2013). Therefore, qualitative data was gained from semi-structured interviews due to their ability to explore a depth of participant understanding and allowed topics to be built upon and interesting avenues that arose during the course of the interview to be pursued further (Byrne, 2012).

Ten semi-structured interviews were conducted with individuals involved in work winning from ten different UK construction contractors. The websites of the top twenty construction contractors by turnover in 2019 were viewed, and introductory emails sent to individuals identified online as being appropriate to the research. Ten positive responses were received. This included three procurement and work winning directors, four bid managers and three senior estimators. The interviews were then conducted over the phone lasting between 45 and 90 minutes. All interviews were recorded and then transcribed, and a process of narrative analysis conducted. Narrative analysis involves data in the form of stories. It is the process of summarising participant responses to reveal their deeper understandings without reducing responses to quantitative variables (Loosemore and Bridgeman, 2018). Such stories can be compared or even grouped together to reveal both similarities and differences of opinions and interpretations, and is increasingly popular as a social science analysis method (Griffin and May, 2012).

\section{FINDINGS AND DISCUSSION}

Analysis of the interviews revealed many consistent findings across all contractors. Firstly, reinforcing trends identified in the industrial survey conducted by KPMG (2017) all interviewees argued that CSR and SV are embraced as a core part of all contractor's business models. There was also a general consensus across all interviewee's that they have increased their social value focus due to the requirements of the SVA. However, all contractors also stipulated that even without the SVA in place during procurement they would still continue with their social value behaviours due to management values. Yet all contractors interviewed also won an element of their annual work from the public sector so this research could not determine the validity of this further. Although this area wasn't the 
focus of this paper, it was an interesting insight and one that is worth further exploration in future research.

When the topic of social value measurement was discussed, all contractors were involved with measurement to different degrees. Again, there was a consensus of all interviewee's which revealed that measurement of social value was utilised to support and enhance social value communications, supporting findings in the literature that social value has objective requirements and needs to be measured and communicated (Loosemore and Higgon, 2016). However, differences in understandings were witnessed in each contractor's perceptions of social value measurement. Whilst each contractor discussed terms and practices that overlapped in places, they all had somewhat different perceptions of social value, that were driven in part from the needs and perceptions of their numerous clients.

In total, six different types of social value measurement tools were utilised by the ten contractors, with all but one using a recognised third-party measurement tool. This illustrates how there appears to be no single market leading social value measurement method, and with each method communicating social value in a different way, this will arguably contribute to the difficulties and confusions that persist in reaching an agreed definition of social value. However, all the measurement tools currently in use attributed monetary metrics to social value. All the measurement tools were of an objective and qualitative nature and so arguably reduced social value down to the figures. Interestingly there was no consistency reported across the six different measurement tools, even when measuring the same social value behaviour. For instance, one contractor reported using two different social value measurement tools across their business operations and adopting a 'pick and mix' approach when it came time to compiling tenders for procurement, or even when reporting on progress to existing clients. The results of whichever tool had the highest monetary output were used, even if this meant using one tool to measure one practice, and a different tool to measure a different practice. The interviews explored this further and revealed the contractor saw no contradiction over the legitimacy of either social value measurement tool. It appears the tools were not questioned or rigorously explored, simply used and exploited for the benefits they brought. 
Analysis of the interviews also revealed that seven of the contractors interviewed felt the social value measurement method they used fully measured and communicated social value. There was a consensus across these seven contractors that social value could be fully measured, and they saw no issues in the reduction of benefits to financial metrics. They were all of the opinion that social value was objective, and once agreed between stakeholders, could be easily measured and communicated using financial metrics. This is despite arguments in the literature that social value means different things to different people (Watts et al., 2019a) and a lack of widely agreed definitions results in social value being difficult to measure and communicate (Loosemore and Higgon, 2016). The three remaining contractors also all believed that social value was objective, and that despite different stakeholder understandings and perceptions, agreements could be reached as to what social value is, and then measurement proxies should be used. Two contractors felt that the majority of social value could be captured in some form of financial metrics but admitted there was some elements of social value that arose from the practices they undertook which could not be accurately captured in monetary terms - but other metrics could be used - the tools to measure such social value just were not available yet. These two contractors believed such social value was impossible to accurately capture at present and so made no effort to do so. Only one contractor interviewed believed there was a need to measure social value using both financial and non-financial metrics, and they were currently considering how best to do this but had no solution at the time of interviewing. All contractors, therefore, only participated in social value practices they were able to accurately measure, and that resulted in a set of financial variables that could be easily communicated to numerous stakeholders. Any social value practices that couldn't be easily measured using currently adopted measurement tools were likely to be ignored or marginalised, with focus shown to social value practices that easily leant themselves to financial measurement.

\section{CONCLUSION}

Construction contractors engage with social value measurement in order to be able to communicate their social value practices and results to stakeholders such as public sector clients, as this will increase the likelihood of successful procurement. However, social value is a subjective concept and so not one that lends itself easily to measurement. Nevertheless, 
contractors are increasingly adopting measurement tools that take an objective approach and reduce social value to monetary figures. Through interviews with ten UK construction contractors, this paper reveals that the majority of contractors interviewed see social value only as that which can be measured with financial metrics, it seems a hammer can only see nails. Whilst some contractors do see the subjective nature of social value posing a problem for measurement in that every aspect cannot be easily measured with financial metrics, at present amongst the vast majority of contractors no effort is being made to measure these practices. In fact, the social value practices that do not result in easy to measure and communicate financial metrics are being largely ignored. The findings of this paper reveal that social value practices which result in a higher amount of social value generated are potentially being ignored for practices which are easier to measure and communicate. Such findings contribute to understanding the ramifications of contractor decisions to measure and communicate social value in objective terms. In practice this may mean public sector clients need to consider the procurement requirements they are imposing on contractors in order to achieve the highest amount of social value possible, and not just that which can be easily condensed to financial terms. Further research could be conducted around understanding what other drivers are behind contractor reporting practices, and also further research could be aimed at establishing how social value practices that do not lend themselves to be financial metrics can be effectively measured and communicated.

\section{REFERENCES}

Arudson, M; Lyon, F; McKay, S. \& Moro, D. (2013) Valuing Social Value? The Nature and Controversies of Measuring Social Return on Investment. Voluntary Sector Review, 4(1), pp.3-18.

Barthorpe, S. (2010), "Implementing corporate social responsibility in the UK construction industry", Property Management, Vol. 28, No. 1, pp. 4-17.

BEIS (2018) Industrial Strategy - Construction Sector Deal https://assets.publishing.service.gov.uk/government/uploads/system/uploads/attachment_ data/file/731871/construction-sector-deal-print-single.pdf Bowen, H. (1953). Social Responsibilities of the businessman. New York: Harper \& Row. Bryman, A. (2016), Social Research Methods, $5^{\text {th }}$ Ed. Oxford University Press, Oxford. 
Byrne, B. (2012). Qualitative Interviewing. In, Seale, C, Researching Society and Culture. $3^{\text {rd }}$ Ed. Sage Publications. London.

Carroll, A. B. (1991). The Pyramid of Corporate Social Responsibility: Toward the Moral Management of Organizational Stakeholders. Business Horizons. 4. p39-48.

Carroll, A. (1999). CSR: Evolution of a definitional construct. Business \& Society, 38. p.268295.

Carter, K. and Fortune, C. (2007) "Sustainable Development Policy Perceptions and Practice in the UK Social Housing Sector", Construction Management and Economics, Vol. 25 No. 4, pp. 399 - 408.

Cresswell, J. (2013). Research Design: qualitative, quantitative, and mixed methods approaches. Sage. London.

Ding, G.K.C. (2008) Sustainable Construction - The role of environmental assessment tools. Journal of environmental management, 86, pp. 451-464.

Griffin, A, and May, V. (2012). Narrative analysis and interpretative phenomenological analysis. In, Seale, C, Researching Society and Culture. $3^{\text {rd }}$ Ed. Sage Publications. London. Griffith, A. (2011). Fulfilling Contractors' Corporate Social Responsibilities using StandardsBased Management Systems. International Journal of Construction Management. 11(2), p37-47

Haapio, A. \& Viitaniemi, P. (2008) a critical review of building environmental assessment tools. Environmental Impact Assessment Review. 28(7), pp. 469-482.

Higham, A.P, Barlow, C, Bichard, E and Richards, A. (2018) Valuing Sustainable change in the Built Envuronment: Using SuROI to appraise built environment projects. Journal of Facilities Management. Vol. 16 No. 3 pp 315-355.

Krley, G., Münscher, R. \& Mülbert, K. (2013) Social Return on Investment (SROI): Stateofthe-art perspectives. Heidelberg: Universtat Heidelberg.

KPMG. (2017), The Road Ahead; The KPMG Survey of Corporate Responsibility Reporting 2017. KPMG Global Sustainability Services 2017.

Loosemore, M. and Bridgeman, J. (2018) The social impact of construction industry schoolsbased corporate volunteering. Construction Management and Economics. Vol. 36 (5), p243258.

Loosemore, M. and Higgon D. (2016). Social Enterprise in the Construction Industry. Routledge, Oxon. 
Rees, W.E. (2009), "The ecological crisis and self delusion: implications for the building sector", Building Research and Information, Vol. 37 No. 3, pp. 300-311.

Rhodes, C. (2015). Construction Industry: statistics and policy. Nr 01432. House of Commons Library. www.parliament.uk/briefing-papers/sn01432.pdf.

Rhodes, C. (2019). Construction Industry: statistics and policy. Nr 01432. House of Commons Library. https://commonslibrary.parliament.uk/research-briefings/sn01432/

Robson, C, and, McCartan, K. (2017). Real World Research. $4^{\text {th }}$ Edition. John Wiley and Sons. London.

Russel, S (2013) Journey to Impact: A Practitioner Perspective on Measuring Social Impact. Midland Heart.

Schweber, L. (2013) The effect of BREEAM on clients and construction professionals. Building Research and Information. Vol. 41 No. 2 pp. 129-145.

Social Impact Investment Taskforce (2014) Impact investment: The invisible heart of markets [Online] available from:

http://www.socialimpactinvestment.org/reports/Impact\%20Investment\%20Report\%20FINA L [3].pdf

Watson, K. J., Evans, J., Karvonen, A., and Whitley, T. (2016). Capturing the social value of buildings: The promise of Social Return on Investment (SROI). Building and Environment, 103, p289-301.

Watts, G., Fernie, S. and Dainty, A. (2019), "Paradox and legitimacy in construction: how CSR reports restrict CSR practice", International Journal of Building Pathology and Adaptation, Vol. 37 No. 2, pp. 231-246.

Watts, G., Ferne, S. and Dainty. A. (2019a). Measuring Social Value in Construction. in: ARCOM 2019 (35th Annual Conference), 2nd-4th September 2019, Leeds Beckett University Wood, C and Leighton, D (2010) Measuring social value: the gap between theory and practice - https://www.demos.co.uk/files/Measuring_social_value_-_web.pdf Zhao, Z., Zhao, X., Davidson, K. and ZUO, J. (2012). A corporate social responsibility indicator system for construction enterprises. Journal of Cleaner Production, 29-30, p.277-289 